\title{
INFLUENCE OF THE LENGTH OF A CYLINDER ON ITS AEOLIAN TONE LEVEL: MEASUREMENT AND MODELLING
}

\author{
WAGNER J. GONÇALVES DA SILVA PINTO ${ }^{1}$, FLORENT MARGNAT ${ }^{1}$ AND \\ CAMILLE NOÛS ${ }^{2}$
}

\author{
${ }^{1}$ Institut Pprime \\ Department of Fluid Flow, Heat Transfer and Combustion \\ Université de Poitiers - ENSMA - CNRS \\ Building B17 - 6 rue Marcel Doré - TSA 41105 \\ 86073, POITIERS CEDEX 9, France \\ Wagner-jose.GONCALVES-DA-SILVA-PINTO@isae-supaero.fr; florent.margnat @univ-poitiers.fr \\ ${ }^{2}$ Cogitamus laboratory
https://www.cogitamus.fr/
camille.nous@cogitamus.fr
}

Key words: Aeroacoustics; bluff-body noise; aeolian tone; airframe noise; Curle's analogy; Aeroacoustic design

\begin{abstract}
The tonal noise generated by the flow over elongated cylinders is measured using microphones in the anechoic wind tunnel BETI of Institut Pprime. The effect of the length to diameter ratio of the cylinder is assessed by varying the diameter from $6 \mathrm{~mm}$ to $20 \mathrm{~mm}$ within the constant width $(750 \mathrm{~mm})$, open jet, test section. The velocity is varied from 10 to $40 \mathrm{~m} / \mathrm{s}$, leading to a Reynolds number range of about $4,000-53,000$. A proper normalization is needed to obtain a good collapse of experimental data from nearly 10 studies on the same evolution in 3 steps: for very short cylinders, the tone level does not depend on the length; for semi-long cylinders, it follows the fourth power of the length to diameter ratio; for very long cylinder, the length's influence vanishes in the form of a sound level asymptote. This sigmoidal evolution is noticed for both the circular section and the square section cylinders, and questions the classical modelling of the aeroacoustic process using compact, coherent segments of cylinder associated with a coherence length to account for spanwise phase loss. Literature data from numerical simulation or experiment using end-plates are included in the analysis too.
\end{abstract}

\section{INTRODUCTION}

The overall goal of this work [1] is the specific influence of shape on aeroacoustics. We choose the simple case of long cylinders as a model for airframe noise. For such a configuration, the flow is determined by the regime, in terms of Reynolds number (Re) and Mach number (Ma), and by the geometry of the body, in terms of cross-section shape and span $\ell$. For almost all the shapes, and at the majority of unsteady regimes, the flow is characterised by periodic vortex shedding, which generates a tonal acoustic radiation. The adimensionalized frequency of the tone is the Strouhal number ( $\mathrm{St}$ ), and its level has been modelled 
in the literature by [2-7]:

$$
\bar{P}^{2}(r)=\frac{\rho_{0}^{2} U_{\infty}^{2} \mathrm{St}^{2} \ell \ell_{c} C_{L}^{\prime 2}}{16 c_{0}^{2} r^{2}}
$$

where $\bar{P}^{2}$ is the acoustic pressure energy in the transverse direction, $\rho_{0}$ and $c_{0}$ are the density and speed of sound, respectively, in the ambient, $U_{\infty}$ is the inflow velocity, $r$ is the microphone distance from the cylinder. The two remaining quantities are key ingredients of the aeroacoustic efficiency: $C_{L}^{\prime}$ is the root mean-square of the sectional lift coefficient and $\ell_{c}$ is the spanwise correlation length. In this work, we have questioned the factor $\mathrm{St}^{2} \ell \ell_{c} C_{L}^{12}$ from an aeroacoustic design point of view, that is asking about what we could tell to designers, who have neither the time nor the mean to conduct computational aeroacoustics, about what will happen in the acoustic field if they change the geometry.

With this approach in mind, several investigations has been combined including numerical [8-11], theoretical $[12,13]$ and experimental $[14,15]$ approaches. The analysis of the microphone signals for different diameters of a circular cylinder lead us to notice a specific influence of span to diameter ratio on the noise level, which is the subject of the present paper.

This is crucial for numerical simulations, and that is how it matches the scope of this symposium about aeroacoustic modelling and numerical simulation. A typical situation occurs when a 2D simulation is conducted, or a 3D one over a relatively short span. In order to validate the simulation, it is compared with experimental data of far-field pressure. But how can the acoustic field from a 2D simulation be compared with measurements? And, in general, the span is longer in the experiment than in the 3D

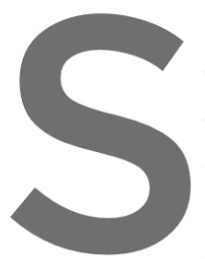
simulation... To enable such coinparisons, some
extrapolate the simulation to the span used in the ex
concept of coherence length of the fluctuating lift, a
of the actual cylinder, with phase relationships dep
shorter or longer than the coherence length. That i
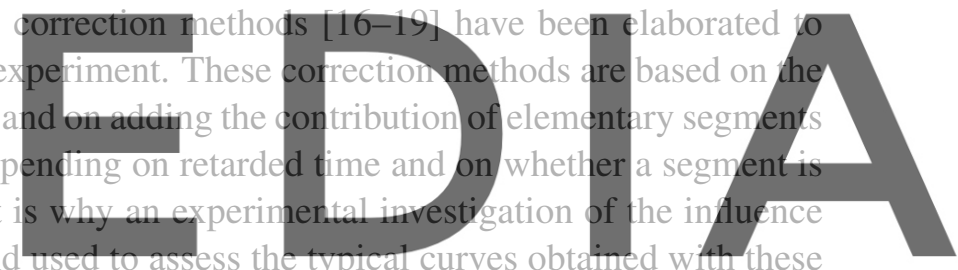
correction methods.

Register for free at https//www.w.scipedia.com to download the version without the watermark The paper is organised as follows? in Section 2 are introduced the present measurements in aeroacoustic wind tunnel. Then available experimental data of noise level emitted by the circular cylinder flow are discussed in Section 3. In Section 4, the influence of length to diameter ratio exhibited by this data is described and compared to the behavior of correction methods. The bad news is that they are different, but this opens the way to a modelling challenge...

\section{MEASUREMENTS IN AEROACOUSTIC WIND TUNNEL}

The cylinder is fixed in the open-jet section of BETI which is the aeroacoustic wind tunnel of Institut Pprime, as shown in Figure 1. The upstream velocity was between 10 and $40 \mathrm{~m} / \mathrm{s}$. The most important parameters here are the exit nozzle, square section side of $70 \mathrm{~cm}$, the anechoic chamber cutoff frequency around $200 \mathrm{~Hz}$, and the microphone distance is one meter. The acoustic pressure signal is recorded during one minute at the sampling frequency of $12.8 \mathrm{kHz}$. The noise spectra are estimated using Welch periodogram method, with a frequency resolution of $1.56 \mathrm{~Hz}$.

The cylinder is larger than the jet so its effective length is close to that of the jet itself, that is $\ell \approx 70 \mathrm{~cm}$. The diameter $d$ is varied from 6 to $20 \mathrm{~mm}$, which leads to a range of 35 to 117 for the span to diameter 

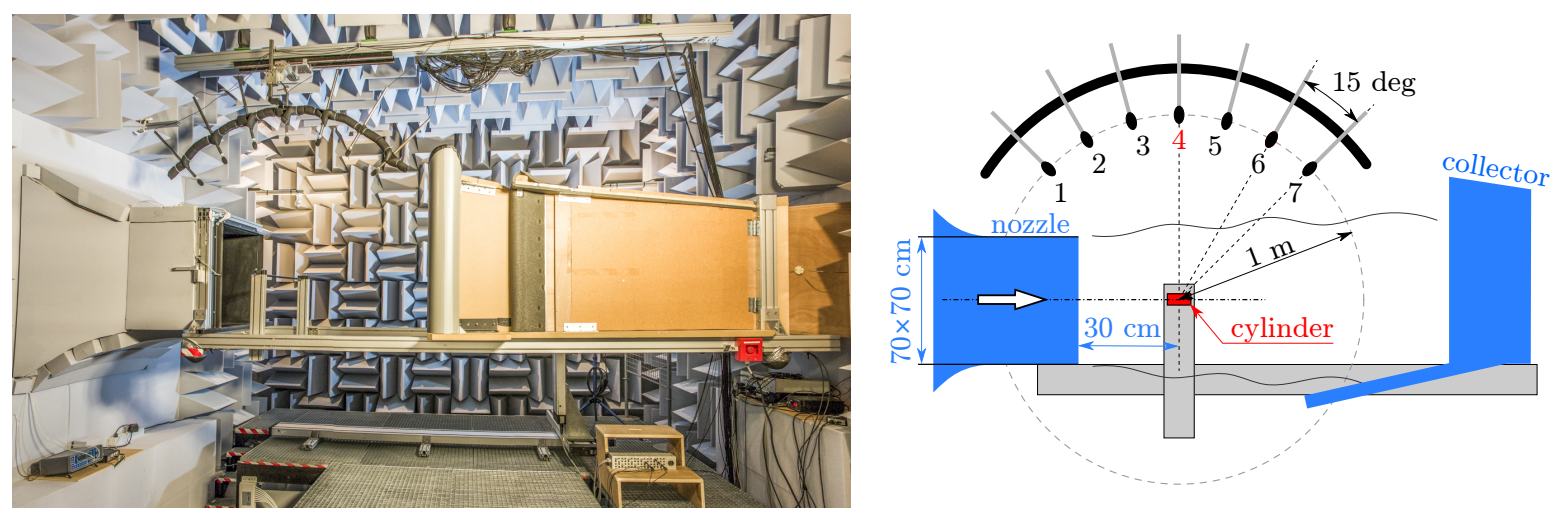

Figure 1: Photo of the anechoic chamber of the wind-tunnel BETI - Institut Pprime, France (left), and diagram of the experimental setup with the microphone array (right). The lower wall of the collector is extended in order to adapt the setup for a fully open jet configuration.

ratio $\ell / d$. Six value of the inflow velocity $U_{\infty}$ were considered in the wind tunnel range, up to $40 \mathrm{~m} / \mathrm{s}$, which corresponds to a very low Mach number (from 0.03 to 0.12). In terms of Reynolds number, these values of the diameter and velocity lead to a range from 4,000 to 50,000 , when taking $1.5 \times 10^{-5} \mathrm{~m}^{2} / \mathrm{s}$ for the kinematic viscosity of air. However, in order to ensure that the three-dimensionalization of the flow be similar, only the cases with a Reynolds number higher than 10,000 were considered in the analysis of the influence of span. The Strouhal number being around 0.2, the tone frequency ranges from $100 \mathrm{~Hz}$ to

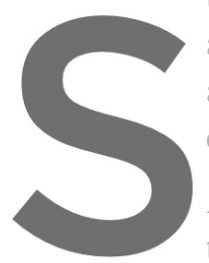
a little bit more than $1 \mathrm{kHz}$. Again, in the analysis of
a tone frequency above $250 \mathrm{~Hz}$ in order to avoid a
chamber frequency cutdff.
As an overview of the measurement results, the po
the flow at $20 \mathrm{~m} / \mathrm{s}$ is shown in Figure 2 (left). Not
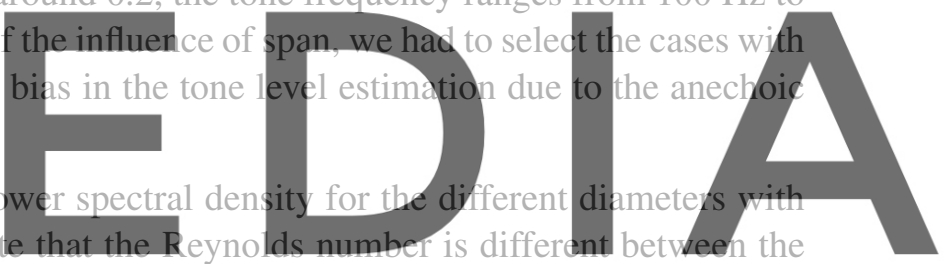
curves. The spectra are qualitatively similar, with a well marked peak at Strouhal number 0.2. Two

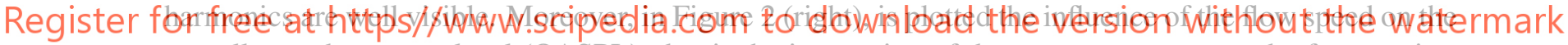
overall sound pressure level (OASPL), that is the integration of the power spectra over the frequencies. It is well fitted by the sixth power law derived by Curle using a compact source assumption.

\section{REVIEW AND NORMALISATION OF LITERATURE DATA}

In order to compare literature and present results, a proper normalisation of the data is needed to account for the different setup and parameters. Consistently with the theoretical formula (1) shown in the introduction, we considered a scaled sound pressure energy $\bar{p}^{2}$, which is the squared acoustic pressure, corrected by the microphone distance to diameter ratio, and divided by the dynamic head, and the Mach number to recover the $U_{\infty}^{6}$ power law, namely:

$$
\bar{p}^{2}=\left(\frac{r}{d}\right)^{2} \frac{\bar{P}^{2}(r)}{\rho_{0}^{2} U_{\infty}^{4}} \frac{c_{0}^{2}}{U_{\infty}^{2}}
$$

The other quantities from (1) that depend on the regime are hard to measure in the same campaign or have weaker influence of the sound radiation for a given shape at similar Reynolds number. A corresponding 

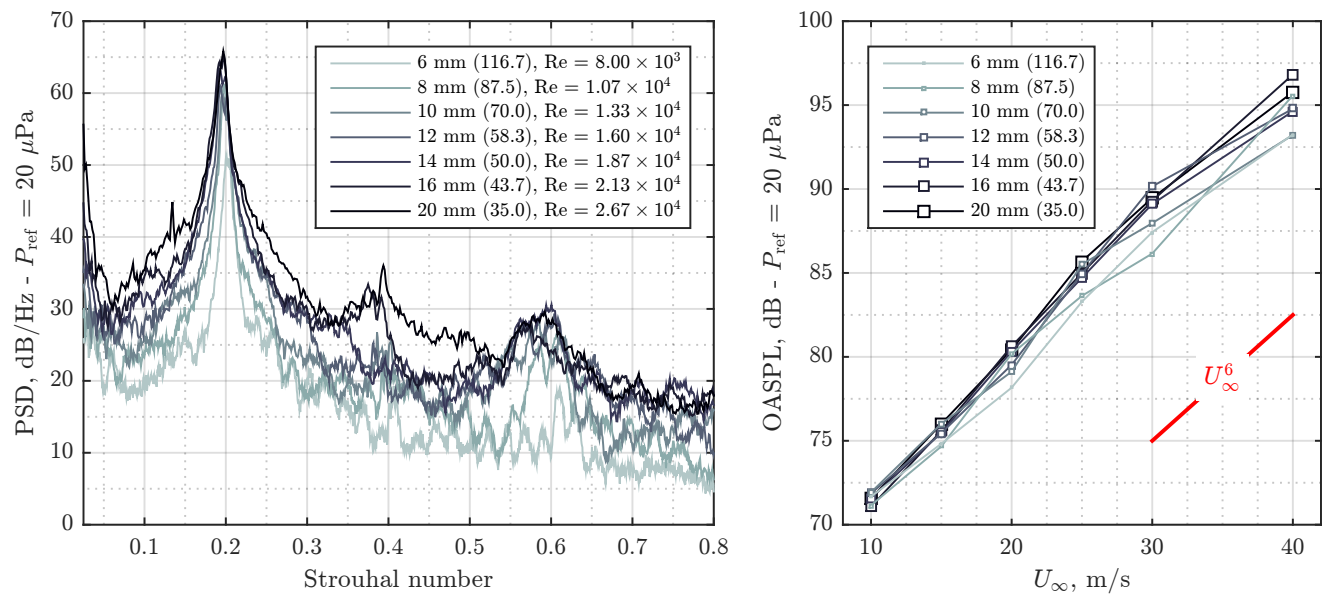

Figure 2: Acoustic pressure power density spectrum for the flow over circular cylinder at $U_{\infty}=20 \mathrm{~m} / \mathrm{s}$ (left), and overall sound pressure level as a function of flow velocity (right). In the legends, the quantity in millimeters is the diameter $d$ and that in parenthesis is the length to diameter ratio $\ell / d$. Both graphs are for microphone 4 , see Figure 1 (right).

level in $\mathrm{dB}$ is defined as usual:

$$
\mathrm{SSPL}=10 \log _{10}\left(\bar{p}^{2}\right)
$$

Regarding the criteria for level at the peak frequenc this paper, only results for criteria is given in [1]. With variables in the theoretical formula (1) are the span
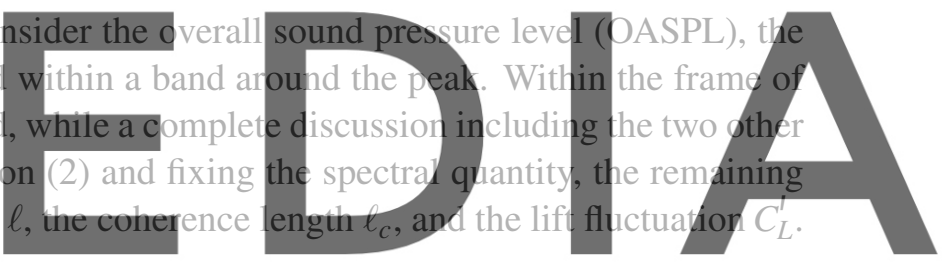

In Table 1, are listed these studies reporting aeolian tone OASPL that we have been aware of. Naturally,

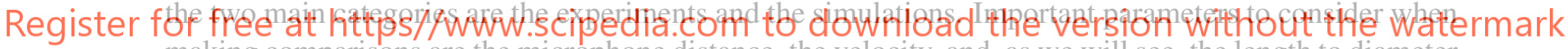
making comparisons are the microphone distance, the velocity, and, as we will see, the length to diameter ratio and the end-condition in the experiments. As illustrated in Figure 3, this can be open, as for the present measurements, when the cylinder is longer than the jet. When it is shorter, or when one end is free for a mounted cylinder, then the setup is called a finite cylinder. Finally, some investigations use end plates, and then the setup is called closed.

Now that the present measurements has been described and the tools for comparison with literature have been set up, the influence of length to diameter ratio is investigated in the next section. 

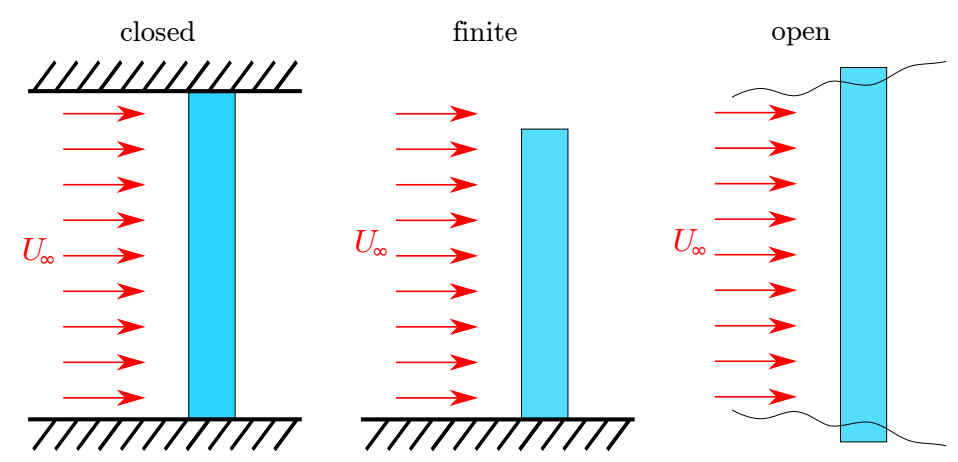

Figure 3: Classification of experimental configurations listed in Table 1.

Table 1: Studies reporting OASPL for circular cylinder flow, in chronological order within each configuration defined in Figure 3.

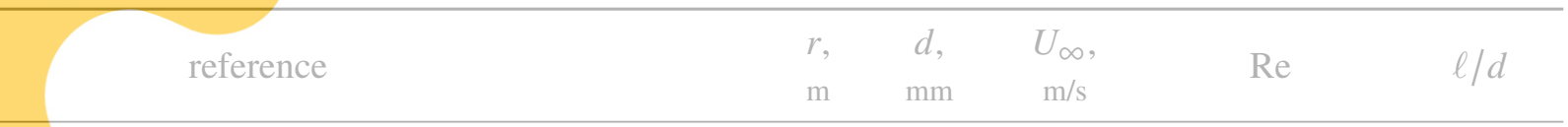
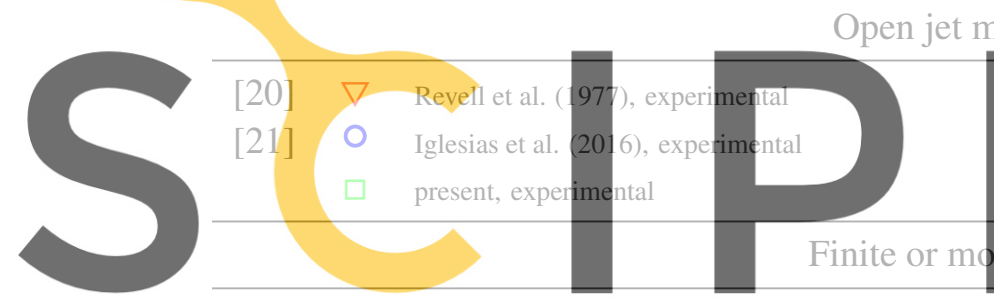

[22] + King \& Pfizenmaier (2009), experimental

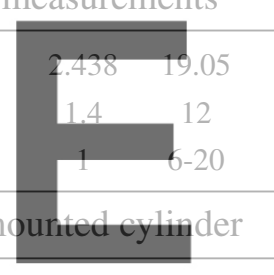

1.420

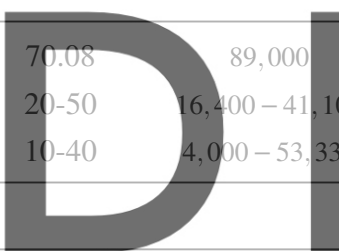

$32-69$

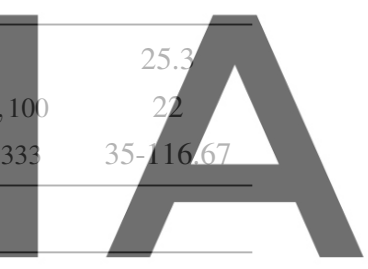

$2-35$

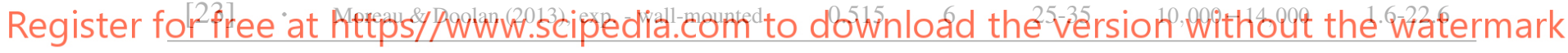
Closed wind tunnel or cylinder with end-plates

\begin{tabular}{|c|c|c|c|c|c|c|c|}
\hline [24] & $\bullet$ & Fink et al. (1976), experimental & 2.25 & 51 & $31-125$ & $105,000-258,000$ & 15.43 \\
\hline [25] & 4 & Iida et al. (1996), experimental & 1.000 & 40 & $3.75-52.5$ & $10,000-140,000$ & 12.5 \\
\hline$[6]$ & $\nabla$ & Casalino \& Jacob (2003), experimental & 1.380 & 16 & 20 & 22,000 & 18.75 \\
\hline [26] & $\star$ & Sueki et al. (2010), experimental & 2.000 & $25-45$ & 27.7 & $46,000-83,000$ & $13.33-24$ \\
\hline \multicolumn{8}{|c|}{ Numerical simulations } \\
\hline [27] & $*$ & Cox et al. (1998), 2D URANS - fully correlated & 2.438 & 19.05 & 68.00 & 90,000 & $5-26.3$ \\
\hline [28] & $\mathbf{\square}$ & Orselli et al. (2009), 2D URANS - fully correlated & 2.430 & 19 & 71.05 & 90,000 & $2.5-25.3$ \\
\hline [28] & $\nabla$ & Orselli et al. (2009), 3D LES - corrected & 2.430 & 19 & 71.05 & 90,000 & 25.3 \\
\hline [29] & $x$ & Karthik et al. (2018), 3D LES + FW-H & 1.400 & 20 & 64 & 84,770 & $3-35$ \\
\hline$[30]$ & + & Du \& Sun (2019), 3D DNS + periodic FW-H & 2.438 & 19 & 68 & 1,000 & $4-248$ \\
\hline
\end{tabular}




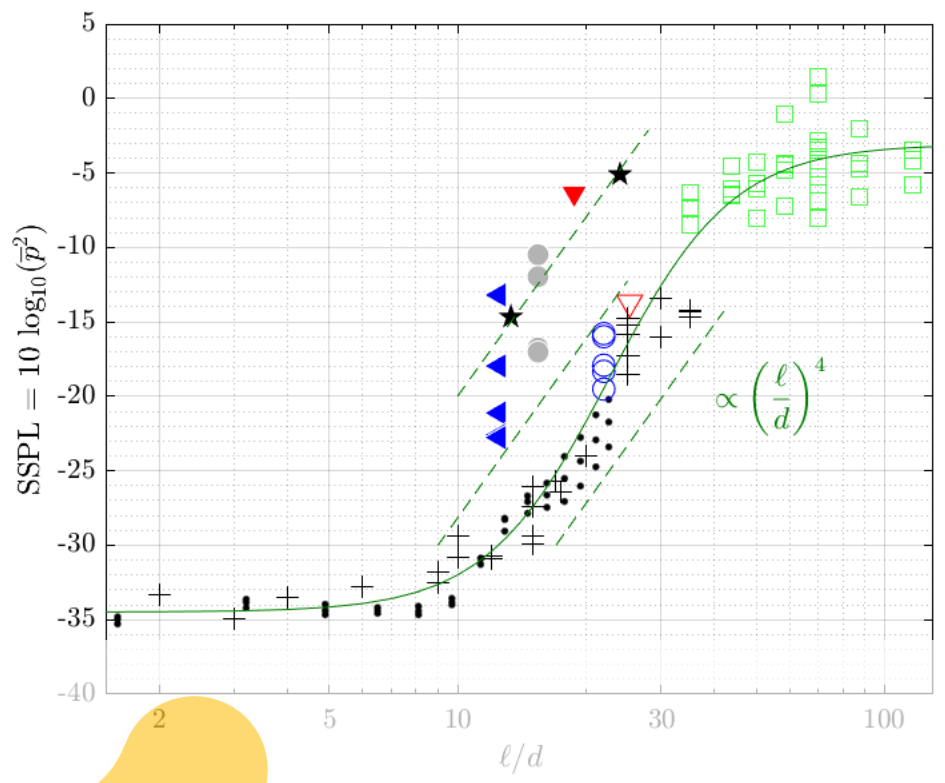

$\nabla$ Revell et al. (1977) [20]

O Iglesias et al. (2016) [21]

$\square$ present

+ King \& Pfizenmaier (2009) [22]

• Moreau \& Doolan (2013) [23]

- Fink et al. (1976) [24]

Iida et al. (1996) [25]

$\checkmark$ Casalino \& Jacob (2003) [6]

$\star$ Sueki et al. (2010) [26]

Figure 4: Influence of span to diameter ratio on the overall, scaled sound pressure level measured in circular cylinder flow. For experimental setups of the cited works, see Table 1. The full line is the sigmoid law (4). Dashed lines show the $\ell / d$ fourth power slope.

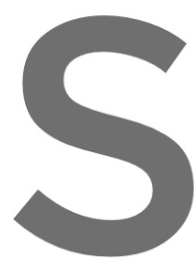

\section{INFLUENCE OF \\ 4.1 Experimental data \\ The relevancy of the present scaling (2) can be noticed in Figure 4 w
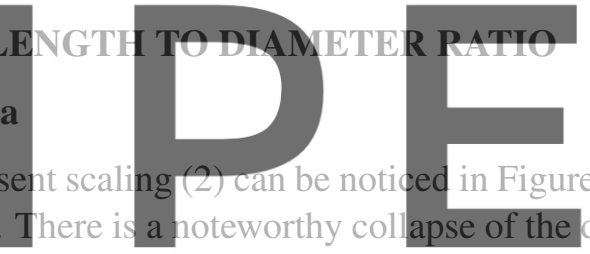
experimental study only. 'Th
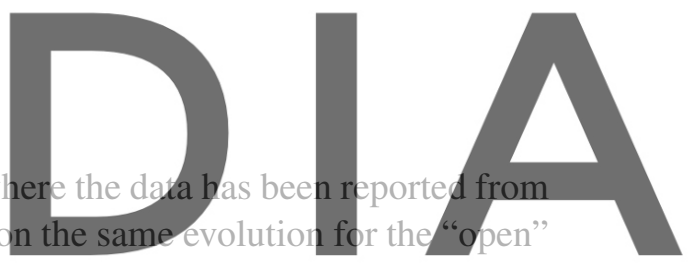

and "finite" configuration (the data for "closed" configurations are discussed hereafter). In particular,

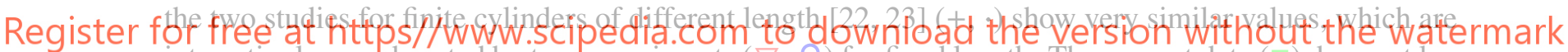
interestingly corroborated by two experiments $(\nabla, O)$ for fixed length. The present data $(\square)$ does not lay

in the same range of span to diameter ratio, however it allows to complete the description of the influence of this geometrical parameter. The latter goes in three steps: for short span, namely $\ell / d \leq 10$, the scaled level appears almost constant; there, the sound radiation may be dominated by $3 \mathrm{D}$ dynamics at cylinder end or interaction with the boundary layer [23]. For $10 \leq \ell / d \leq 30$, a very strong increase of SSPL with increasing span is noted, which may corresponds to a dominance of the tonal radiation associated with lift fluctuation at the shear-layer flapping frequency. For longer cylinders, present data shows a saturation of the SSPL, possibly due to destructive interferences between source regions along the span.

This three-step evolution can be modelled by a sigmoid function, that is an algebraic growth between two constants:

$$
\log _{10}\left(\bar{p}^{2}\right)=\frac{\pi}{1+\beta\left(\frac{\ell}{d}\right)^{-\gamma}}+\log _{10}\left(\bar{p}_{0}^{2}\right)
$$

with $\beta \approx 11,630, \gamma=-3$ and $\bar{p}_{0}^{2} \approx 3.559 \times 10^{-4}$, obtained by non-linear regression [1]. Although the quality of the regression is good, there is some dispersion. In particular, the influence of velocity is not 
fully accounted by the sixth power law, resulting in level differences for the same span to diameter ratio in most of all the experiments.

One surprising result is the slope of the curve in the intermediate range, that is for cylinders 15 to 30 diameter long. The fourth power slope bounds the data quite well, while the maximum slope of the sigmoid curve is even greater. Before discussing this further, the data from experiments using end plates, that is the closed configuration, shall be considered. Available data is only for the intermediate spans, but, as shown in Figure 4, the scaled level is systematically higher than for the the finite or open configuration of same span to diameter ratio. This level increase has been explained in the literature by a stabilizing effect of end plates on the flow $[22,31]$ or by an acoustic effect such as reflexion and image sources. In spite of this level difference due to the setups, the influence of span seems to remain unchanged. The fourth power slope is very clear for the data from Sueki et al. [26] ( $\star$ ), which is also well consistent with that from Casalino \& Jacob [6] ( $\nabla)$. The two other studies $[24,25](\bullet, \varangle)$ reported results for a single span at different velocities, leading to more dispersion, but they do not contradict the trend.

This fourth power slope is surprising because the classical formula (1) leads to a maximum slope of two, yet this would only be obtained if the lift were in phase all along the span. Actually, $\ell_{c}$, the spanwise correlation or coherence length is rather of a few diameters at these regimes. This means that the theory behind this formula misses something about the influence of span or about the link between span, spanwise coherence and sectional lift.

4.2 Assessing models and correction methods
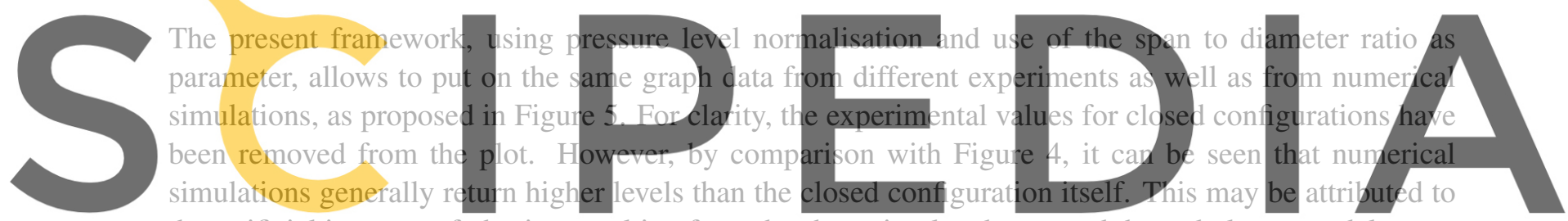

the artificial increase of phasing resulting from the short simulated span and the turbulence model.

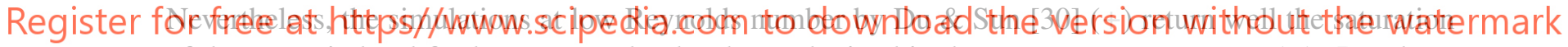

of the acoustic level for large spans that has been obtained in the present measurements ( $\square$ ). But these three studies $(*, \square,+)$ that tested different spans reported levels that follow a square law, consistently with the method they used to extrapolate their 2D or short span flow simulation to larger span acoustic prediction. Moreover, the value reported by Orselli et al. [28] using a correction method ( $($) ) is consistent with a linear increase of the scaled level with $\ell / d$ adjusted for a same radiation of the segment used for the flow simulation.

Finally, only the recent 3D simulations of finite cylinders by Karthik et al. [29] $(\times)$ seem to return a higher slope for intermediate spans like that noticed in the experiments.

\section{CONCLUSION}

While investigating the influence of cross section shape on aeolian tone level, a very strong influence of the span itself has been unearthed. Three distinct behaviors have been observed, being the medium cylinder range $(10<\ell / d<30)$ the most driven one by the cylinder span. For all regions in graph, observed trends do not align with classical compact cylinder noise description. It should be remarked that the sigmoid evolution with high slope for intermediate spans has been noticed for the square cylinder too, 


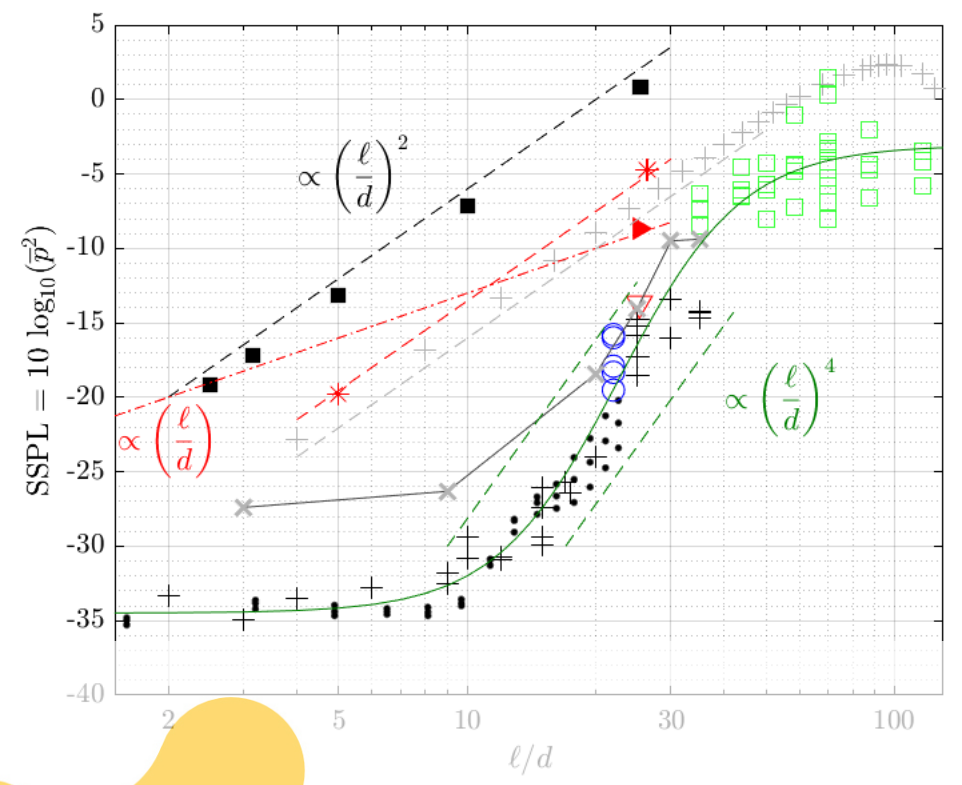

$\nabla$ Revell et al. (1977) [20]

O Iglesias et al. (2016) [21]

$\square$ present

+ King \& Pfizenmaier (2009) [22]

- Moreau \& Doolan (2013) [23]

* Cox et al. (1998) [27]

Orselli et al. (2009) [28]

$>$ Orselli et al. (2009), - corrected [28]

$\times$ Karthik et al. (2018) [29]

+ Du \& Sun (2019) [30]

Figure 5: Influence of span to diameter ratio on the overall, scaled sound pressure level reported in experimental and numerical studies. For material and methods of the cited works, see Table 1. The full, green line is the sigmoid law (4). Dashed lines and dash-dotted line show the $\ell / d$ second and first power slope, respectively. Full, grey line for visual aid only.

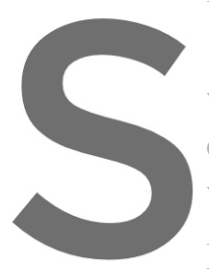

with the same constant for short bodies [1]. The d
only in numerical extrapolations of short, fully ph
when considering the noise emission of very long oy

Back to the classical formula (1), the span could in
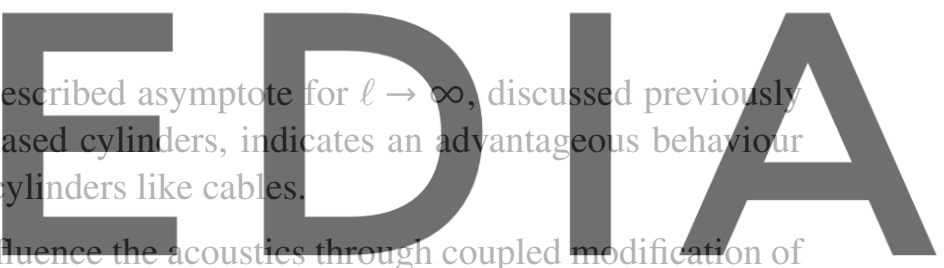

the correlation length and the sectional lift fluctuation. Or the present observations may be considered as

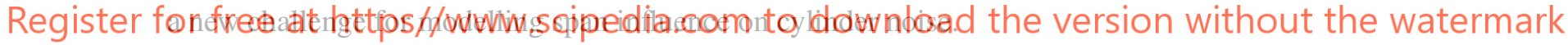

\section{Acknowledgement}

The PhD funding of the first author was provided by the Ministère de l'Enseignement Supérieur et de la Recherche (MESR, french Ministry of Higher Education and Research), which is greatly appreciated. The authors are also grateful to Janick Laumonier, Laurent Philippon and Pascal Biais for their fundamental contributions to the present experiments.

\section{References}

[1] W. J. Gonçalves da Silva Pinto, Modelling airframe noise: from aerodynamic topology to acoustic efficiency. PhD thesis, University of Poitiers, Oct. 2019.

[2] N. Curle, "The influence of solid boundaries upon aerodynamic sound," Proceedings of the Royal Society of London A: Mathematical, Physical and Engineering Sciences, vol. 231, no. 1187, pp. 505-514, 1955.

[3] O. M. Phillips, "The intensity of aeolian tones," Journal of Fluid Mechanics, vol. 1, no. 6, 
p. 607-624, 1956.

[4] Keefe, "An investigation of the fluctuating forces acting on a stationary circular cylinder in a subsonic stream and of the associated soud field (utia report no. 76)," tech. rep., Institute of Aerophysics, University of Toronto (UTIA), 1961.

[5] P. Leehey and C. Hanson, "Aeolian tones associated with resonant vibration," Journal of Sound and Vibration, vol. 13, no. 4, pp. 465 - 483, 1970.

[6] D. Casalino and M. Jacob, "Prediction of aerodynamic sound from circular rods via spanwise statistical modelling," Journal of Sound and Vibration, vol. 262, no. 4, pp. 815 - 844, 2003.

[7] H. Fujita, "The characteristics of the aeolian tone radiated from two-dimensional cylinders," Fluid Dynamics Research, vol. 42, no. 1, p. 015002, 2010.

[8] W. J. G. S. Pinto, F. Margnat, and Y. Gervais, "Influence of cross-section on the aeolian tone: a numerical study in the laminar regime," in 25th AIAA/CEAS Aeroacoustics Conference (Aeroacoustics 2019), 20-24 May, Delft, The Netherlands, 2019.

[9] W. J. G. da Silva Pinto and F. Margnat, "Shape optimization for the noise induced by the flow over compact bluff bodies," Computers \& Fluids, vol. 198, p. 104400, 2020.

[10] W. J. G. da Silva Pinto and F. Margnat, "A shape optimization procedure for cylinders aeolian tone," Computers \& Fluids, vol. 182, pp. 37 - 51, 2019.

[11] F. Margnat and V. Morinière, "Behavior of an immersed boundary method in unsteady flows over

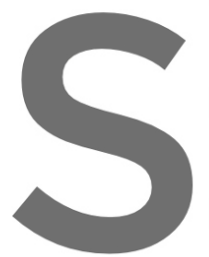
sharp-edged bodies,

[12] F. Margnat, "Hybrid dence," Computer W. J. G. S. Pinto, F. Margnat, and C. Noûs the onset of unsteadiness: infftence of bluff-b
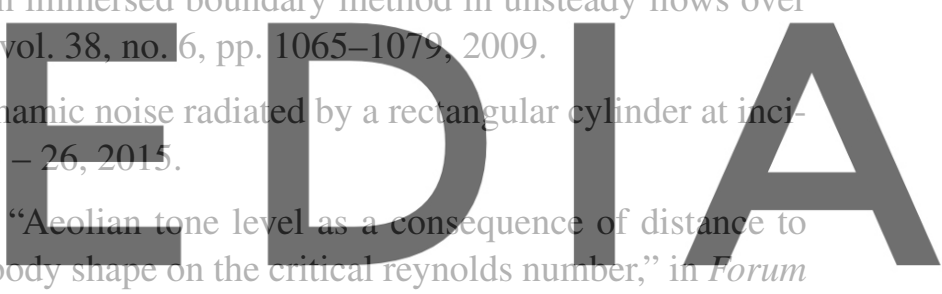
Acousticum, 7-11 December, Lyon, France, 2020

Register for free at https//www.scipedia.com to download the version without the watermark spanwise coherence length of the flow over a bluff body," in Forum Acousticum, 7-11 December, Lyon, France, 2020.

[15] W. J. G. S. Pinto, F. Margnat, and Y. Gervais, "Effect of cross-section on flow three-dimensionality for prismatic bodies and the associated noise emission," in 25th AIAA/CEAS Aeroacoustics Conference (Aeroacoustics 2019), AIAA Paper 2019-2531, (Delft, The Netherlands), 20-24 May 2019.

[16] C. Kato, A. Iida, Y. Takano, H. Fujita, and M. Ikegawa, "Numerical prediction of aerodynamic noise radiated from low Mach number turbulent wake," American Institute of Aeronautics and Astronautics, 1993.

[17] F. Pérot, X. Gloerfelt, C. Bailly, J.-M. Auger, and H. Giardi, "Numerical prediction of the noise radiated by a cylinder," in 9th AIAA/CEAS Aeroacoustics Conference and Exhibit, Aeroacoustics Conferences, American Institute of Aeronautics and Astronautics, 2003.

[18] J. H. Seo and Y. J. Moon, "Aerodynamic noise prediction for long-span bodies," Journal of Sound and Vibration, vol. 306, no. 3, pp. 564 - 579, 2007. 
[19] C. J. Doolan, "Computational bluff body aerodynamic noise prediction using a statistical approach," Applied Acoustics, vol. 71, no. 12, pp. 1194 - 1203, 2010.

[20] J. D. Revell, R. A. Prydz, and A. P. Hays, "Experimental study of airframe noise vs. drag relationship for circular cylinders," Tech. Rep. Final Report for NASA Contract NAS1-14403, Lockeed Report 28074, Feb. 1977.

[21] E. L. Iglesias, D. Thompson, and M. Smith, "Experimental study of the aerodynamic noise radiated by cylinders with different cross-sections and yaw angles," Journal of Sound and Vibration, vol. 361, pp. $108-129,2016$.

[22] F. King and E. Pfizenmaier, "An experimental study of sound generated by flows around cylinders of different cross-section," Journal of Sound and Vibration, vol. 328, no. 3, pp. 318 - 337, 2009.

[23] D. J. Moreau and C. J. Doolan, "Flow-induced sound of wall-mounted finite length cylinders," AIAA Journal, vol. 51, no. 10, pp. 2493-2502, 2013.

[24] M. R. Fink, R. H. Schlinker, and R. K. Amiet, "Prediction of rotating-blade vortex noise from noise of nonrotating blades," tech. rep., National Aeronautics \& Space Administration, 1976.

[25] A. Iida, H. Fujita, C. Kato, and T. Otaguro, "Experimental investigation of the generation mechanism of aerodynamic noise: 2nd report, on correlation between surface pressure fluctuation and aerodynamic sound radiated from a circular cylinder (in japanese)," Transactions of the Japan Society of Mechanical Engineers Series B, vol. 62, no. 604, pp. 4160-4167, 1996.

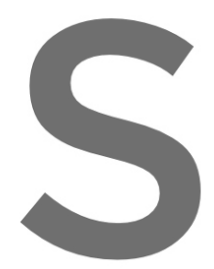

[26] T. Sueki, T. Takais n sound from bluff

[27] J. S. Cox, K. S. Bren for a circular cylinde
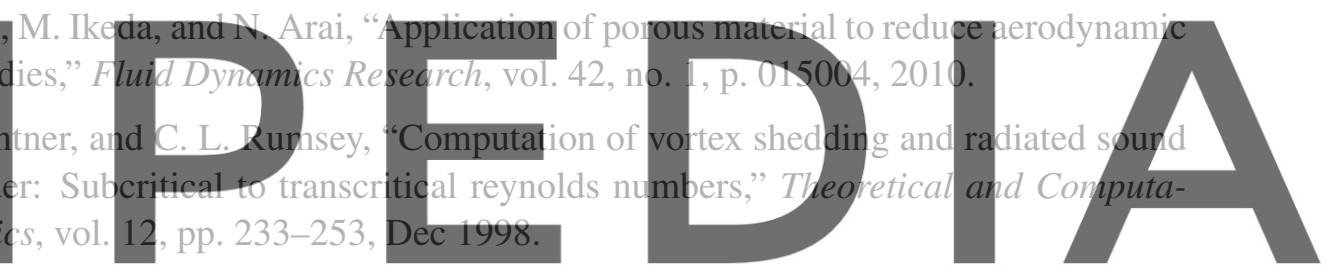

[28] R. Orselli, J. Meneghini, and F. Saltara, "Two and three-dimensional simulation of sound gener-

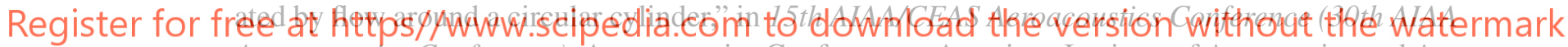
Aeroacoustics Conference), Aeroacoustics Conferences, American Institute of Aeronautics and Astronautics, 2009.

[29] K. Karthik, S. Vengadesan, and S. K. Bhattacharyya, "Prediction of flow induced sound generated by cross flow past finite length circular cylinders," The Journal of the Acoustical Society of America, vol. 143, no. 1, pp. 260-270, 2018.

[30] L. Du and X. Sun, "Noise reduction by feedback rotary oscillation of a three-dimensional circular cylinder," Journal of Fluids and Structures, vol. 84, pp. 421 - 439, 2019.

[31] Szepessy, "On the control of circular cylinder flow by end plates," European Journal of Mechanics, vol. 12, no. 2, pp. 217-244, 1993. 